\title{
GOVERNMENT INTERVENTION TO FACIAL MASK FOR COVID-19 AND ITS IMPACT
}

\author{
Yiqun Li \\ Undergraduate of Applied Economics, business faculty, Macau University of Science and Technology
}

\begin{abstract}
Making government control the producing of personal protective equipment, especially facial masks, is one of the keys to confronting the shock during the pandemic of COVID-19 in China. Attribute to the high-infectivity of pneumonia, the demand of facial mask had dramatically increased. I conduct a theorical model to analyze the reason why the supply will not satisfy the demand in short run without government regulation, using utility change due to panic and elasticity of facial mask. Since intervention of central government, the concern of overcapacity and hazard of intended hoarding had been eliminated, masks were allocated efficiently. More chances of international trade would be brought in both short and long run.
\end{abstract}

Keywords: government intervention; demand; supply; overcapacity; allocation; international trade

DOI: $10.36012 / \mathrm{ems} . \mathrm{v} 1 \mathrm{i} 2.1831$

\section{Intrdouction}

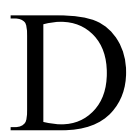

ue to the shock brought by the pandemic of COVID-19, demand of personal protective equipment, especially facial mask, had dramatically increased in China, which was confirmed to be an effective measure people should take to protect themselves. This kind of pneumonia was definitely a new disease with uncertainty, which arose panic among the public. People are self-interest, so they will purchase enough masks resorting to any ways. The production could not accelerate in short period with large scale. Factories could not produce enough masks for the sudden augment. Depend on the market itself, the conflict would not be handled.

Chinese central government took aggressive and powerful act to control the production, allocation and sale of mask, supplied masks directly for the hospitals, and appointed certain drug stores as the selling points. People needed to draw lots or take turns to purchase necessary masks. All the measures made the society stable and deal with the conflict between supply and demand in short run. After domestic pandemic had been controlled, Chinese government switched its policy to export, provide support to international partners.

\section{Conflict of Supply and Demand}

I would like to use to adopt several methods to figure out why the demand of mask would rocket and why the supply could not satisfy the demand in short period.

\subsection{Demand}

\subsubsection{Utility}

At the beginning of this pandemic, uncertainty of the coronavirus triggered gigantic fear among the public. The lack of special-effect medicine and seasonal migration made the situation much worse. In this scenari$\mathrm{o}$, wearing masks became the only several viable ways to self-protect. Consumers are self-interested, thus, they will take advantage of every resource they had access.

The model of Cobb-Douglas utility function can be applied to the analysis.

$$
\mathrm{U}=\mathrm{A}^{*}\left(\mathrm{x}^{\wedge}(\mathrm{a})^{*} \mathrm{y}^{\wedge}(1-\mathrm{a})\right),(0<\mathrm{a}<1)
$$

By which, the $\mathrm{A}$ is a constant. $\mathrm{X}$ and $\mathrm{Y}$ are assumed to be two kinds of goods, and in this scenario, the $\mathrm{x}$ is referred to the consumption of facial masks, the $y$ is referred to all the other goods except the masks.

In normal period, masks are not crucial to most consumers, if they do not have any inspiratory system disease or are allergic to pollen. The numerical value of a will not be so high, even negligible. Consumption of other goods contribute to most of utility. We can deviate such an equation as following.

$$
\mathrm{U}=\mathrm{A}^{*}\left(\mathrm{x}^{\wedge}(0.001) * \mathrm{y}^{\wedge}(0.999)\right)
$$

However, when the unexpected catastrophe happened, masks became indispensable. People started to be fearful to go out, which meant being exposed to the potential risk of infection. The routine ways of entertainment were forbidden, 1-a also dropped. On another 
hand, people had to go outside to purchase the necessary supple and commodity, which meant they must wear masks. Masks became the insurance of normal life. The a would definitely go upper. So, the new equation was:

$$
\mathrm{U}=\mathrm{A}^{*}\left(\mathrm{x}^{\wedge}(0.3) * \mathrm{y}^{\wedge}(0.7)\right)
$$

In order to maintain the quality or utility, people had no choice but to purchase the mask as much as possible.

\subsubsection{Elasticity}

Since masks became more and more important, the elasticity will undoubtedly increase. An equation can be assumed:

$$
\mathrm{D}=\mathrm{A}^{*} \mathrm{p}^{\wedge}(\mathrm{c})
$$

By which, $\mathrm{A}$ is a constant.

Masks were necessary to us, meanwhile, became less elastic. The graph below can clearly illustrate the elasticity change.

Most of consumers are risk aversion, they could compare the cost and benefit on mask-purchase. Under this circumstance, since people might die of this pneumonia, increasing the expenditure on self-protection would be an optimal option. Thus, demand on masks change less with the price. Consumers care less about the price, because they confirmed that wearing masks was the only viable way to protect themselves.
Considering the GDP per capita of China in 2019, which had outnumbered 10 thousand dollar, and Per-capita disposable income, which had outnumbered 30 thousand CNY in 2019, consumers had enough money for this purchase.

Assume that all the parameters and exogenous variables were as same as before. Assume that the price of one mask was $3 \mathrm{CNY}$, and each person had to use one mask per day and had one person they needed to take care of, such as the child or their parents. Ex penditure per month could be deviated, which was approximately $180 \mathrm{CNY}$. The $180 \mathrm{CNY}$ was only 7.2 percent of income people could spend, which occupied relevantly small fraction. People could also use their savings and borrow money and apply for loan to conquer the pandemic.

\subsection{Supply}

Capacity of masks were 20 million per day in China originally. How ever, since this pandemic happened in Spring Festival, which caused several domino effects. The shortage of labor, restriction of freeways and no preparedness made joint effort. Full capacity could not be achieved. Even did, the capacity did not meet the tremendous demand.

At the beginning, people around the world enlarged the global purchase and managed to get more

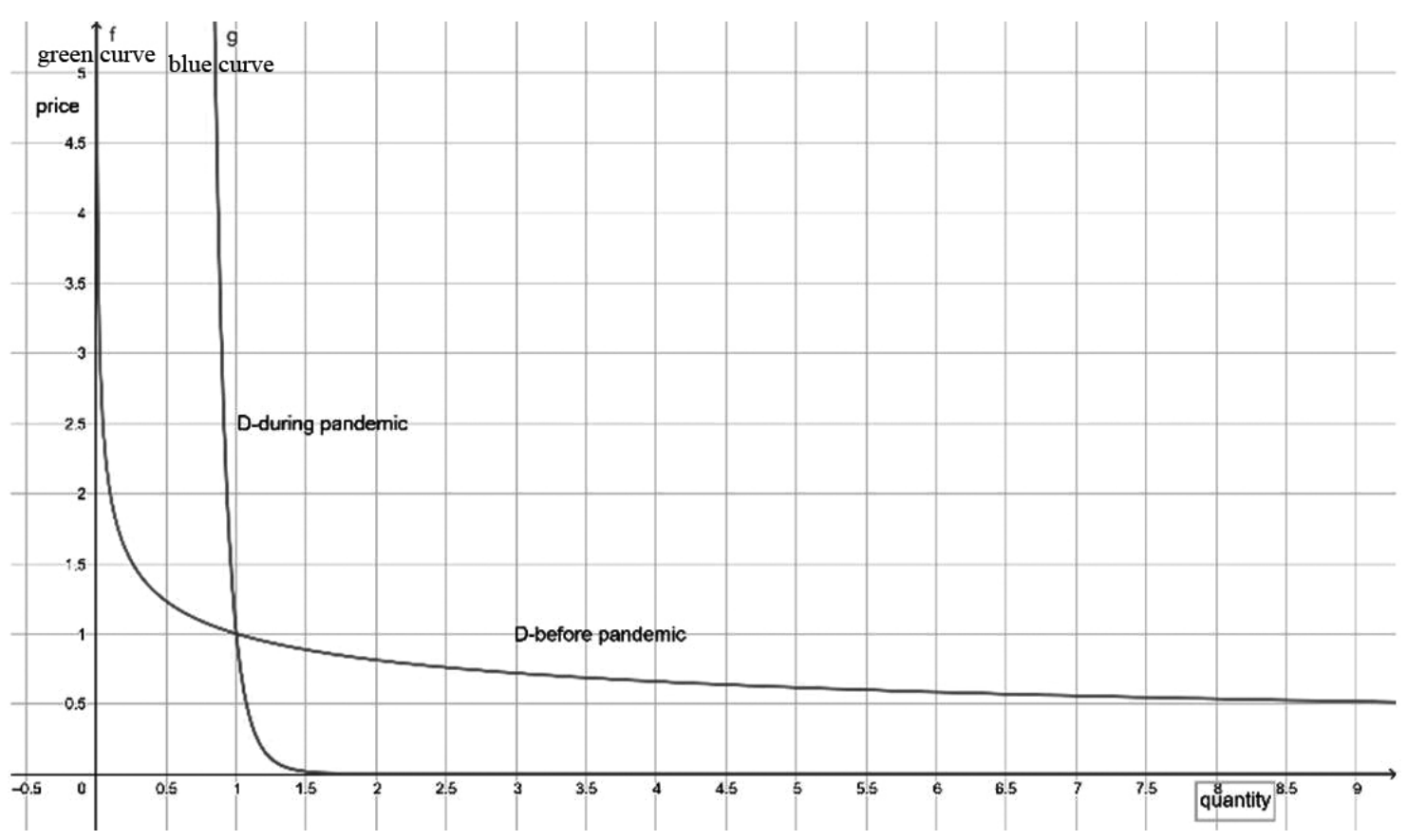

Note: the green curve manifests demand before the pandemic, and the blue curve represents demand of facial masks during pandemic.

From the graph, we can compare how willing consumers would be to purchase masks. 
than 100 million masks. However, attribute to the time on passing the custom, these masks could not be sent to mainland China immediately. To some extreme, global purchase relieved the burden in China, but not eliminated.

Population of China was 1.4 billion. Considering that people had to consume one mask when they went out, and the frequency of going out was 0.1 , due to the policy of reducing social contact and self-quarantine, consumption of mask per day was 140 million units. There was no way to satisfy the demand without expanding the capacity.

In brief, the optimal solution was expanding the capacity as much as possible, meanwhile, reducing the consumption of masks. However, solely depending on the market itself could not reach the new equilibrium.

\section{Government Regulation}

Since the analysis on the conflict between supply and demand has been made, one expedient solution is to resorting on the government intervention. Just like in America, which has Defense Production Act, however, this time Chinese Government took more comprehensive and aggressive action to fulfill government's duty.

The detailed actions could also be divided into two parts, allocation and producing.

\subsection{Allocation}

One of the major concerns was that some people might take advantage of this pandemic, which meant they probably hoarded so many masks intendedly and re-sold them in extremely high price. Such behavior would definitely lead to the unfair distribution in the society. Rich people have the privilege to purchase more masks, and the relatively poorer people had no extra ability to buy the life-saving shelter. In such a scenario, only full-covering of masks would block down the infection effectively. Anyone, here was those poorer and weaker people, without masks would be vulnerable, and made others' efforts invalid. So, one urgent action needed to be taken was to eliminate the hazard of hoarding masks in large scales intendedly.

To do this, government adopted two typical policies, drawing lots to select who could purchase masks as auxiliary action and distributing masks to residents directly as main action.

\subsubsection{Distribution}

Distribution had long history in China. This time, in several cities, like Shanghai, neighborhood committees would decide a specific time point, give the residents a warrant-like permit and ask them to purchase masks in a same quantity. Those people had purchased once had to waited for an interval time and could purchase again only after this period. More importantly, the permit manifested that people could not purchase as many masks as they wanted.

News that people purchased hundreds of masks and re-sold on Wechat platform triggered the panic and rage on the unfair distribution. After the adoption of policy, although masks were still scarce, at least, people could satisfy their basic need for survival. According the law of diminishing utility, the value of first five was larger than the last five one of 1000 masks. To some extent, this policy maximized the utility of society. .

\subsubsection{Drawing lots}

Drawing lots was widely taken in the fields, such as purchase of plate number or house.

During this pandemic happened in mainland China, some of the electronic shopping platform, such as JD and Taobao, and even local government, drew lots to select who were qualified to purchase the masks in order to handle the issue of mask shortage.

This action was controversial actually. Superficially, it was a fair way, because everyone had the equal probability to win for the right to purchase extra masks, considering of the limited labor force and inventory. And the procedure was also simple enough to conduct.

However, it ignored consumers' motivation, because consumers could not be ranked in the degree of requirement. The people who really need the masks more might not have the chance. And some extreme case would also be a big issue, those who had never been selected during several procedures had to suffer more pressure than others, which would never be helpful the panic-easing and stabilization. Solely depending on drawing draw was not even one effective way to reach fair distribution.

\subsection{Producing}

One of the major obstacles was how to improve the capacity in the shortest time. People confirmed that the pandemic of COVID-19 was periodical, which meant overcapacity was a tangible problem producer had to 
confront. What's more, since pandemic happened in the Spring Festival, only a few labor forces were available and no enough raw materials were prepared. Undoubtedly, the cost of producing would dramatically increase. Combined with the law that the price of mask could not increase, people were not willing to produce because they were losing money. Sense of duty and patriotism would not work because operating cash flow could not sustain the producing for long period and would soon be exhausted .

Government took two main policies, giving the subsidies to the producers and making promise to deal with the upcoming overcapacity.

\subsubsection{Subsidy}

Normally, cost of producing a mask is lower than 1 CNY. However, the cost escalated fast during the pandemic. One key component, melt-blown nonwovens, could be used as an exemplification. Compared with 20 thousand CNY normally, the cost of such fabric climbed to 400 thousand CNY per year. Partially because of the scarcity, but more is that some people hoarded it intendedly to earn illegal money . Under such a circumstance, the cost of masks would definitely increase and crush down entire companies.

Although new policies clearly stated that the price of masks would not rise, government give producers subsidies directly to offset the loss of producing. Overwhelming money were coming to the factory. Some companies received 30 thousand $\mathrm{CNY}$ for purchasing the raw materials per ton, which made ends meet; government also supervise the suppliers of melt-blown fabric and simplify the relevant forms and procedures, including application of loan, to eliminate the obstruction faced by mask producer.

\subsubsection{Overcapacity}

Overcapacity in some particular field, such as manufacture of steel, was a serious problem in mainland China, which was also a key issue needed to be solved. Some entrepreneurs were worried about overcapacity, since all the money they invested to purchase machines to produce masks would become sink cost.

According to the statement issued by the State Department, government would purchase all the extra medical resource for reserve and encourage every company to enlarge their capacity as much as possible.

Effectively eliminated the worry on overcapacity, and, what's more, it dealt with the shortage of masks or other resources reserved by the central government to brace for disaster like this pandemic. Government required to replenish the shortage, since all the resources had been distributed to medical workers and protecting vulnerable individuals.

Another way to handle the overcapacity was to sell masks to foreign countries. Europe and America were also hit by pandemic. Without government, negotiation between foreign buyers and China suppliers would not free. Buyers needed to check the quality of masks, and suppliers needed to spend long time to wait for the passing of custom. However, valid government intervention would change it. Goods donated and sold by government would be guaranteed, and government could shorten the procedure of custom and delivery. Foreign buyers would be more willing to purchase goods from China, because it would be more convenient.

\section{Impact on Economy}

After analyzing the advantages and disadvantages of government regulation, the impact could be divided into two parts, domestic economy and international trade.

\subsection{Domestic}

Masks, the most important personal protective equipment, would keep the entire society in normal order. People would only be willing to go back to work with enough protection, especially masks. On another hand, without enough masks, it would increase the risk of being infected in factories and other working places.

With the policy of enlarging capacity of facial masks, supply of masks could be guaranteed, and people started to work again.

\subsection{International}

Pandemic spread to the whole world in March. According to the data realized on 29th March, highest mortality in Italy and biggest population of infected patients in America made the international trade on the brink of collapse. Masks were no longer necessary only in China, but all countries. Attribute to the lack of personal protective equipment, many countries shut down their broader and restricted the international flight in order to slow down the spread of pandemic. Factories shut down and people kept cash in their hands, which made both international supply and de- 
mand decrease. In this scenario, importance of Chinese government-controlling masks-producing also appeared, in both short and long run.

\subsubsection{Short run}

The most urgent problem needed to be fixed by new countries sunk in pandemic was how to make sure they had a stable personal protective equipment source.

Considering the unique influence, such as Italy, and high trade amount with other countries, such as South Korea, shutdown of international trade would undoubtedly bring negative influence to China's economy, which mostly depends on export. Helping those countries back to normal orbit would not only benefit foreign countries, but China itself. According to the news, Spain made an order of more than 550 million masks and France of 1 billion masks from China, which could not be satisfied by signal company. Government played a role of negotiator, it collected the demand of foreign countries and distributed it to producing factories, which definitely improved efficiency and reduced negotiation fee. Government could deploy special plane to transfer the goods directly to terminals.

In short run, new trade potentials were explored to offset the decline of trade amount of other traditional goods. To some extent, international trade of China was temporarily built on personal protective equipment export.

\subsubsection{Long run}

Most investors are risk-aversion, they may not keep investing in pandemic. Solely depending on monetary policy could not deal with companies' trouble, they needed more funds. During the process of exporting masks, China also enlarged the investment of other fields. Chinese government encouraged domestic investors to increase their investment to support those foreign companies to conquer the suspend of cash flow. Chinese "one Belt and one Road" Initiative played a critical role, expanded new investment, kept energy supplies and improved the integration between China and other participants. The more investment made countries struggled with COVID-19 avoid potential unemployment and recover their supply and demand soon.

All the support, including personal protective equipment, medical equipment and necessary consumable items, could narrowed down the distance of each country and enhance trust, which would be conducive to further international trade in future. By this way, China gained more opportunities.

\section{Conclusion}

In sum, at the beginning of pandemic, government should control personal protective equipment producing companies, including masks, simultaneously to brace for the impending impact.

Due to the analysis on the conflict between supply and demand, the demand of masks would rocket and outpace the supply immediately. Solely depending on market itself would never be enough, because causes of the shortage was multiple and beyond its regulation ability. People needed to resort to valid and powerful policy and government intervention. Highly efficient allocation would definitely eliminate the hazard of hoarding masks intendedly. Subsidy should be given to the producers to avoid their loss, according to the specific situation of each country, and overcapacity could be handled by government purchase and global selling. Government could export personal protective equipment as support and help to foreign countries, by this way, in exchange for future international trade opportunity. Government intervention is helpful to both domestic pandemic-controlling and relieve the burden of economy.

\section{Reference}

[1] National Health Committee of China (2020) Guideline of regular medical protective equipment in response to pneumonia of COVID-19.

[2] Jeffrey M. Perloff (2011) Microeconomics with Calculus. Berkeley: Pearson Press.

[3] Liu helu (2020) Research on price restriction by government on facial masks during pandemic, Decision-Making \& Consultancy, 87-91.

[4] Chang Haoyu (2019) Analysis of economics on impact of drawing lots fixing price on market of real estate, Economic Research Guide, 131-132.

[5] China textile (2020) Hengjian Jiangsu: triple salary but same-price mask, China Textile, 40.

[6] Bei Qing (2020) Several ways to handle the shortage of melt-blown nonwovens, China Business Times.

[7] Lin Yifu, Wu Hemao, Xing Yiqing (2010) "tide phenomenon" and the formation of overcapacity, Economic Research Journal, 4-19.

[8] Shen Guobing (2020) The Impacts of Global Spread of COVID-19 Epidemic on International Trade and the Corresponding Countermeasures. 